\title{
Aluminum nano-cantilevers for high sensitivity mass sensors
}

\author{
Davis, Zachary James; Boisen, Anja
}

Published in:

5th IEEE Conference on Nanotechnology, 2005.

Link to article, DOI:

10.1109/NANO.2005.1500709

Publication date:

2005

Document Version

Publisher's PDF, also known as Version of record

Link back to DTU Orbit

Citation (APA):

Davis, Z. J., \& Boisen, A. (2005). Aluminum nano-cantilevers for high sensitivity mass sensors. In 5th IEEE Conference on Nanotechnology, 2005. IEEE. https://doi.org/10.1109/NANO.2005.1500709

\section{General rights}

Copyright and moral rights for the publications made accessible in the public portal are retained by the authors and/or other copyright owners and it is a condition of accessing publications that users recognise and abide by the legal requirements associated with these rights.

- Users may download and print one copy of any publication from the public portal for the purpose of private study or research.

- You may not further distribute the material or use it for any profit-making activity or commercial gain

- You may freely distribute the URL identifying the publication in the public portal

If you believe that this document breaches copyright please contact us providing details, and we will remove access to the work immediately and investigate your claim. 


\title{
Aluminum nano-cantilevers for high sensitivity mass sensors
}

\author{
Zachary J. Davis and Anja Boisen \\ Department of Micro and Nanotechnology (MIC), Technical University of Denmark (DTU), building \\ 345east, 2800 Kgs. Lyngby, Denmark
}

\begin{abstract}
We have fabricated Al nano-cantilevers using a very simple one mask contact $U V$ lithography technique with lateral dimensions under $500 \mathrm{~nm}$ and vertical dimensions of approximately $100 \mathrm{~nm}$. These devices are demonstrated as highly sensitive mass sensors by measuring their dynamic properties. Furthermore, it is shown that Al has a potential higher sensitivity than $\mathrm{Si}$ based dynamic sensors. Initial testing of these devices has been conducted using a novel scanning electron microscope setup were the devices were tested under high vacuum conditions. The $Q$-factor was measured to approximately 200 and the mass sensitivity was measured to 2 attograms $/ \mathrm{Hz}$ by depositing electron beam induced carbon at the end of the nano-cantilever.
\end{abstract}

Index Terms - Nanoelectromechanical systems (NEMS), mass sensor.

\section{INTRODUCTION}

Cantilever based dynamic sensors have in recent years been a platform for highly sensitive mass sensors [1]-[3] and have demonstrated higher sensitivities than commercial Quartz microbalance technologies [4]. A cantilever based mass sensor works by measuring changes in its resonant frequency due to mass changes. Intuitively, by decreasing the size of the cantilever it is possible to measure smaller mass changes. The mass sensitivity can be derived using the equation for the resonant frequency and is given by [1]-[3],[5]:

$$
\left|\frac{\partial m}{\partial f}\right|=\frac{2 m}{f} \text {. }
$$

$f$ is the resonant frequency and $m$ is the mass of the resonator. This equation confirms that by decreasing the mass and increasing the frequency of the mechanical resonator the mass sensitivity is increased.

Current published works have reported attogram $/ \mathrm{Hz}$ mass sensitivity [1],[3]. This has been possible by miniaturizing the cantilever by means of using the emerging nano-lithography techniques such as electron beam lithography on single crystal Si substrates [6],[7]. In this work we report on Al nano-cantilevers as a suitable replacement for $\mathrm{Si}$ based mechanical resonators. It will be shown that higher mass sensitivities can be achieved using $\mathrm{Al}$ and a very simple process flow is presented, which uses standard contact UV lithography to achieve sub 500nm wide cantilevers with thickness of approximately $100 \mathrm{~nm}$. Finally, initial testing of the Al nano-cantilevers using a scanning electron microscope setup will be presented, which has been used to measure the devices resonant frequency, Q-factor and mass sensitivity.

\section{DESIGN}

By looking at the device as a whole, the cantilever must be excited into resonance in order to detect the change in resonant frequency. Making the cantilever very short would increase the mass resolution of a cantilever based sensor; however this is not a viable design. By decreasing the length of the cantilever the stiffness is increased and thus larger forces are needed for dynamic actuation. However, by rewriting the equation for the resonant frequency of a rectangular cantilever [7], it can be shown that the resonant frequency can be increased by decreasing both the Young's modulus $(E)$ and the density $(\rho)$ of the cantilever material, if the thickness $(t)$, width $(w)$ and spring constant $(k)$ of the cantilever are unchanged.

$f=0.408 \frac{k^{2 / 3}}{t w^{2 / 3}} \cdot \frac{1}{\rho^{1 / 2} E^{1 / 6}}$

TABLE I

The calculated length, resonant frequency and mass sensitivity for different cantilever materials. The cantilevers have a spring constant of $0.1 \mathrm{~N} / \mathrm{m}$, a thickness of $100 \mathrm{~nm}$ and a width of $1 \mu \mathrm{m}$.

\begin{tabular}{c|r|r|r|r|r}
\hline \hline Material & $E(\mathrm{GPa})$ & $\rho\left(\mathrm{g} / \mathrm{cm}^{3}\right)$ & $l(\mu \mathrm{m})$ & $f(\mathrm{kHz})$ & $\partial m / \partial f(\mathrm{ag} / \mathrm{Hz})$ \\
\hline $\mathrm{Al}$ & 74 & 2.70 & 5.70 & 2.61 & 1.18 \\
\hline $\mathrm{Poly}-\mathrm{Si}$ & 160 & 2.33 & 7.37 & 2.49 & 1.45 \\
\hline $\mathrm{Si}(100)$ & 180 & 2.33 & 7.66 & 2.44 & 1.43 \\
\hline $\mathrm{Ti}$ & 110 & 4.51 & 6.50 & 1.89 & 3.07 \\
\hline $\mathrm{Cr}$ & 140 & 7.19 & 7.04 & 1.44 & 6.98 \\
\hline $\mathrm{Ni}$ & 200 & 8.90 & 7.94 & 1.22 & 11.48 \\
\hline $\mathrm{Au}$ & 80 & 19.3 & 5.85 & 0.96 & 23.19 \\
\hline \hline
\end{tabular}

In table 1 the mass sensitivity $(\partial m / \partial f)$ is calculated for cantilevers with different materials. The spring constant of each cantilever is kept constant at $0.1 \mathrm{~N} / \mathrm{m}$ by adjusting only the length of the cantilever and maintaining a width of $1 \mu \mathrm{m}$ and a thickness of $100 \mathrm{~nm}$. By looking at table 1 it 
is seen that $\mathrm{Al}$ has the best mass sensitivity followed by poly-Si and then single crystal $\mathrm{Si}$. This is because $\mathrm{Al}$ has both a low density and low Young's modulus compared to the other cantilever materials. Among these materials, which are readily available for MEMS fabrication, $\mathrm{Al}$ is the best choice.

\section{FABRICATION}

In fig. 1 the fabrication of the $\mathrm{Al}$ nano-cantilevers is shown, which is based on a lift-off technique. The devices are realized on 4" Si wafers, fig. 1a. First, a resist mold is formed on the Si substrate using UV lithography, fig. $1 \mathrm{~b}$. Then, $\mathrm{Al}$ is deposited using e-beam evaporation, fig. 1c. Next, the Al deposited on the resist is removed by lift-off, fig. 1d. Finally, the metal structure is released by dry etching the underlying $\mathrm{Si}$ using an isotropic $\mathrm{SF}_{6}$ based dry etch, fig. $1 \mathrm{e}$.

(a)

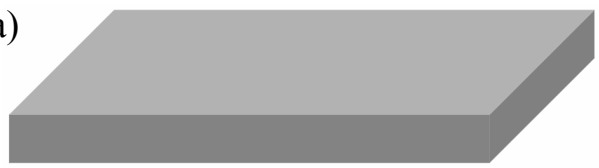

(b)

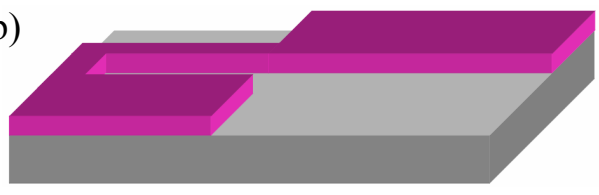

(c)

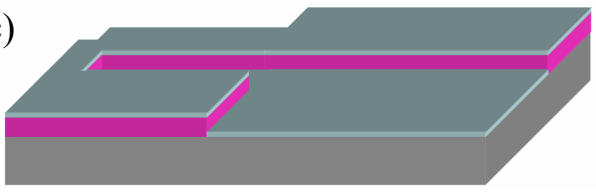

(d)

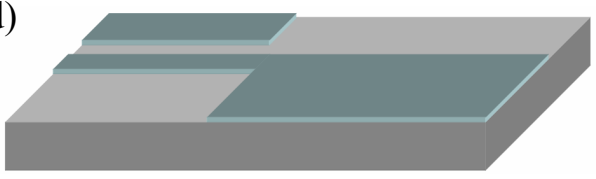

(e)

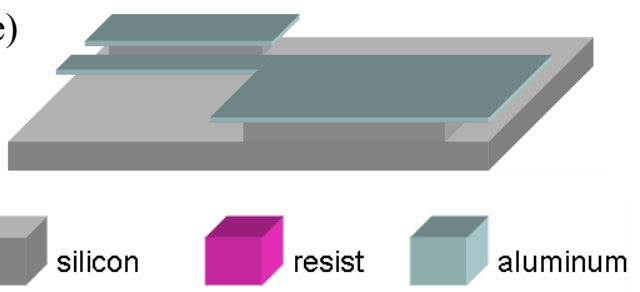

Fig. 1. Process flow of Al nano-cantilevers. (a) silicon substrate. (b) photolithography is used to make a resist mold. (c) A $100 \mathrm{~nm}$ thick Al layer is deposited. (d) the resist mold is etched, lifting off the Al on top of it. (e) the Si substrate is etched to release the $\mathrm{Al}$ structures.
The most critical step in the fabrication is the definition of the resist mold. In order to achieve sub $500 \mathrm{~nm}$ cantilever widths a reverse lithographic process with AZ5214 photoresist was used [8]. Another important aspect of this process is that the release step is performed by dry etching, which alleviates stiction problems that are often seen using wet release techniques.
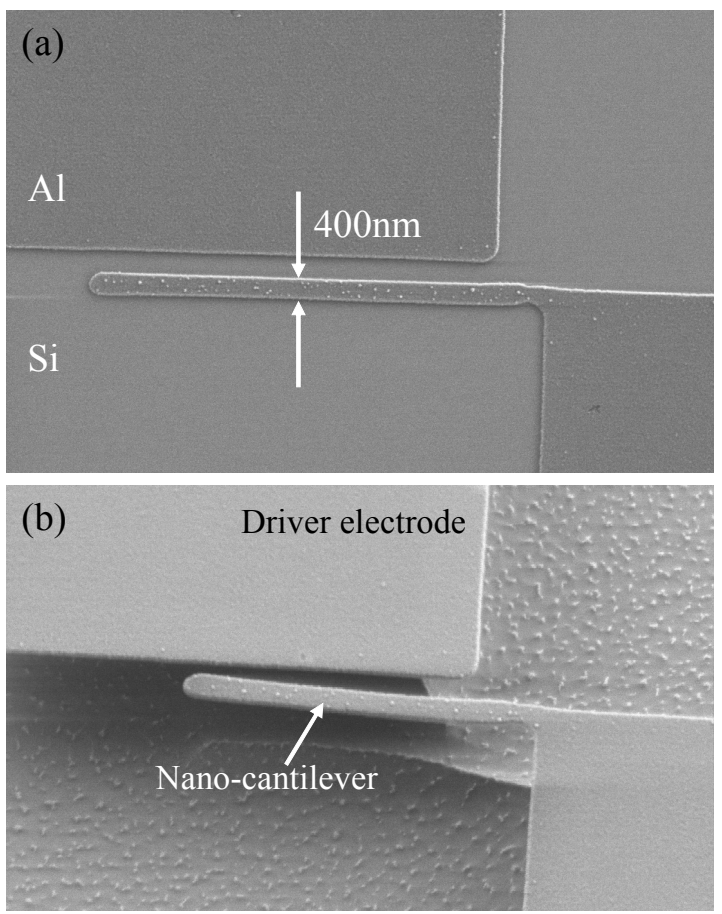

Fig. 2. SEM images of Al nano-cantilever before (a) and after (b) dry underetching.

In fig. 2 scanning electron images (SEM) are shown of the Al cantilever devices before and after dry underetching. From the images it is seen that the width of the nano-cantilever is below $500 \mathrm{~nm}$ and the thickness is approximately $100 \mathrm{~nm}$. The length of the realized nanocantilevers range from $1-10 \mu \mathrm{m}$.

\section{CHARACTERIZATION}

In order to characterize the $\mathrm{Al}$ nano-cantilevers in a vacuum environment the devices where wire bonded to a PCB substrate and placed inside a SEM. Electrical feedthroughs in the SEM facilitate electrical connection to the $\mathrm{Al}$ nano-cantilever chips. On the chip an AC and DC voltage is applied between the driver electrode and the $\mathrm{Al}$ nano-cantilever (fig. 2b), which will actuate vertical motion. Vertical actuation is achieved because of two reasons; (1) the electric field is non-uniform above and below the cantilever due to the Si substrate and (2) the released nano-cantilever bends slightly upwards due to 
internal stress, which also creates a non-uniform electric field. Two SEM based methods of measuring the frequency response of the nano-cantilever were used; (1) sweeping the actuation voltage frequency and imaging the nano-cantilever at a given actuation frequency and (2) focusing the e-beam on the cantilever and monitoring the secondary electron detector signal as a function of the actuation voltage frequency using a gain-phase analyser.
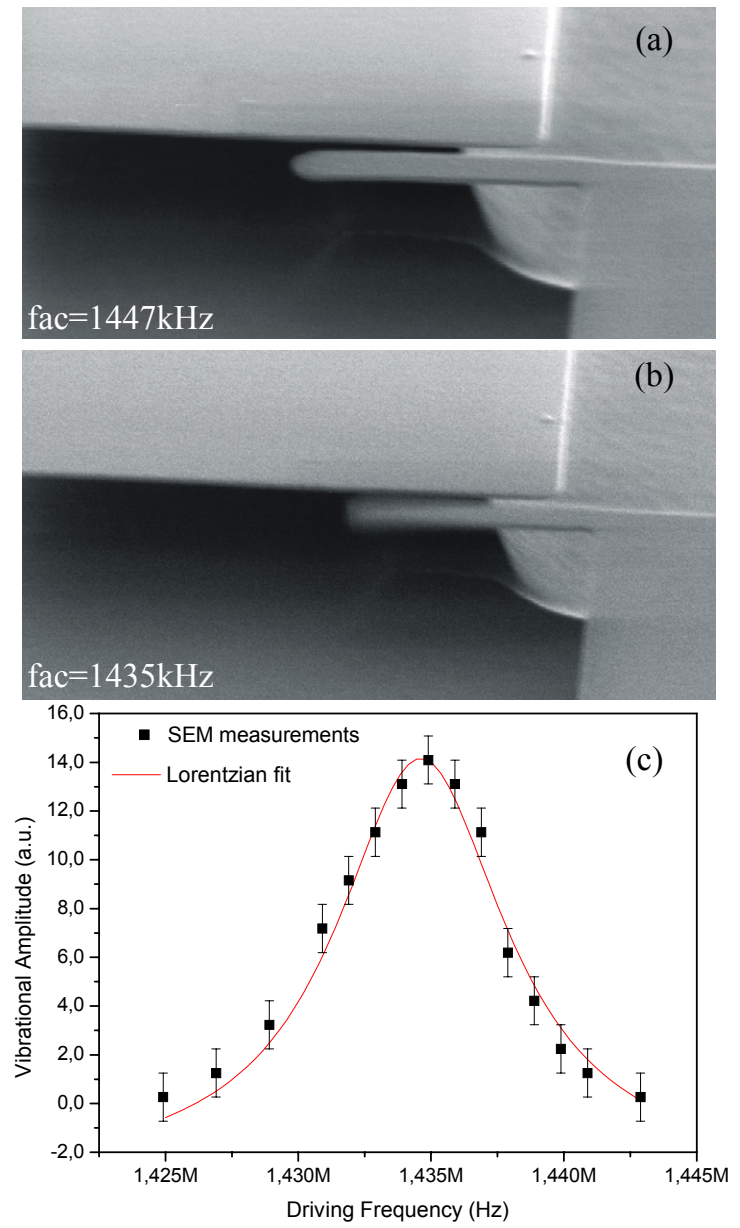

Fig. 3. SEM images of a nano-cantilever out of resonance (a) and in resonance (b). (c) the measured frequency response using the visual measurement method and a Lotentzian fit.

In fig. 3 two SEM images of an Al nano-cantilever are seen at two different actuation frequencies. In this experiment an $\mathrm{AC}$ actuation voltage of $9 \mathrm{Vpp}$ was used. In fig. $3 \mathrm{a}$ the nano-cantilever is not in resonance and the image of the cantilever is sharp, whereas in fig. $3 \mathrm{~b}$, at an actuation frequency of $1435 \mathrm{kHz}$, the end of the cantilever is blurred due to the vibration. In fig. $3 \mathrm{c}$ the frequency response of this device is seen by measuring the amplitude directly from the images taken at different actuation frequencies. From the SEM images the vibrational amplitude can be measured with an accuracy of approximately $30 \mathrm{~nm}$. In order to measure the Q-factor a Lorentzian fit was made and the Q-factor was extracted. In this case the Q-factor was measured to approximately 200. Considering the high vacuum conditions this Qfactor is very low. However, several factors can contribute to this, such as poor anchoring conditions due to underetching of the support (see fig. 2b) and surface losses due to the large surface to volume ratio of these nano-cantilevers $[9,10]$.

By using the $2^{\text {nd }}$ measurement method the frequency response was measured using the same device and is shown in fig. 4. In this measurement an $\mathrm{AC}$ voltage of $1 \mathrm{~V}$ and a DC voltage of $10 \mathrm{~V}$ was used. In fig. 4 it is seen that the detector signal shifts abruptly at the resonant frequency. The reason for this abrupt shift is not fully understood, however it could be due to a non-linear behavior that is seen for large vibrational amplitudes [11]. Another aspect of this measurement is that the resonant frequency is measured here to approximately double the first experiment. This is because in the first experiment the actuation of the cantilever was done with a pure $\mathrm{AC}$ signal between the driver electrode and cantilever, thus the $\mathrm{AC}$ frequency is half the electrostatic force frequency since the forces are proportional to the voltage squared. In the second experiment the $\mathrm{DC}$ voltage was much larger than the $\mathrm{AC}$, thus the $\mathrm{AC}$ signal and the electrostatic force have the same frequency. The theoretical expected resonant frequency (neglecting spring softening effects) of an $\mathrm{Al}$ cantilever with these dimensions is approximately $3 \mathrm{MHz}$, which confirms our measurements.

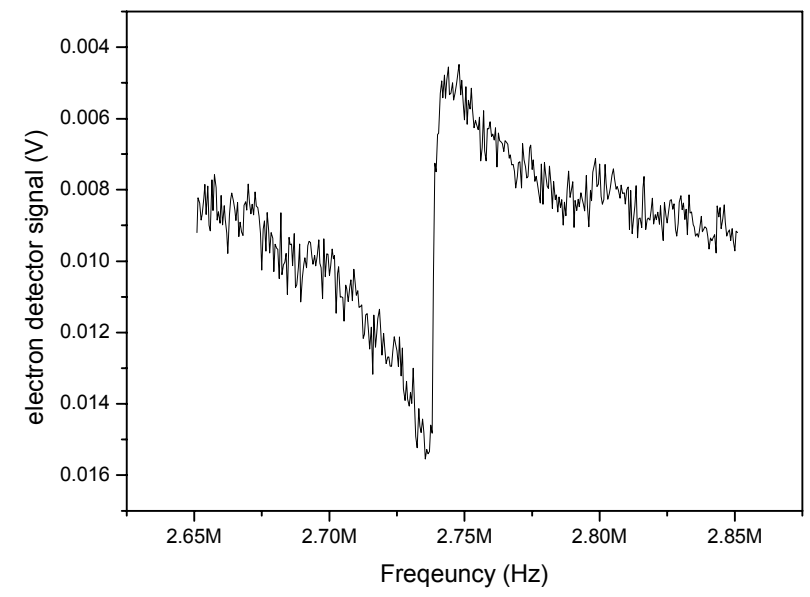

Fig. 4. Measured frequency response of the same device shown in fig. 3, using the electron detector signal versus the actuation frequency. 


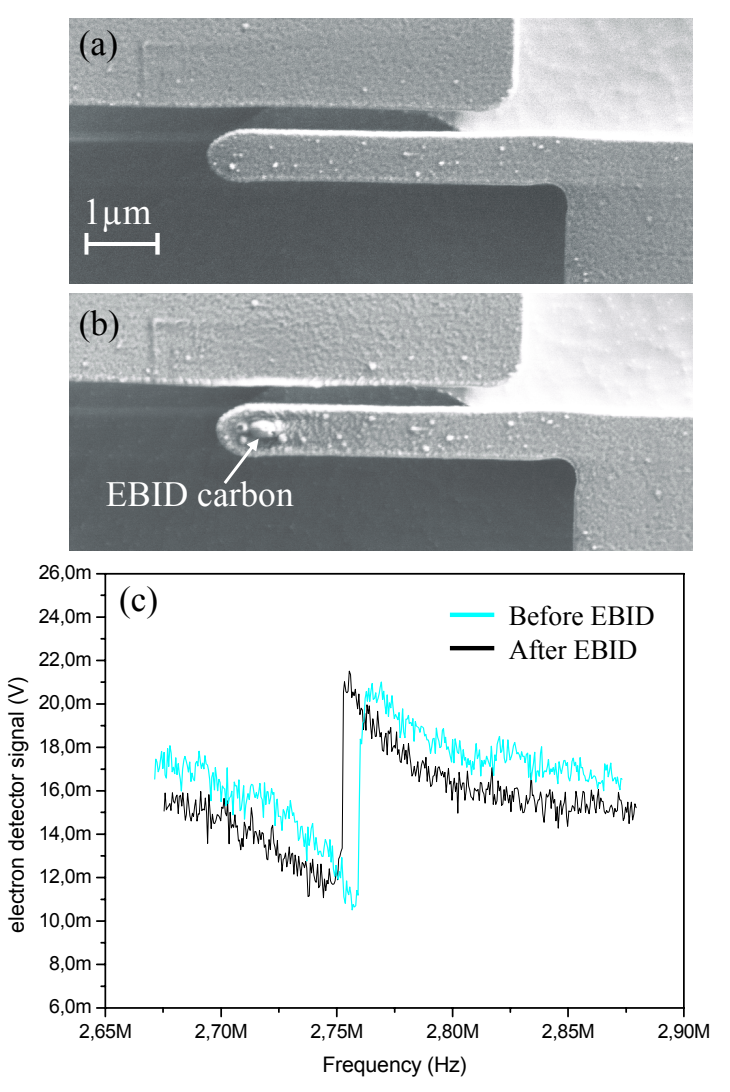

Fig. 5. SEM images of a nano-cantilever before (a) and after (b) carbon deposition and (c) the measured frequency responses both before (red) and after (black) carbon deposition.

\section{MASS MEASUREMENT}

A mass measurement has been performed by depositing carbon by electron beam induced deposition (EBID) [12]. In fig. 5 images of the $\mathrm{Al}$ nano-cantilever are seen both before (a) and after (b) the EBID. Also, the frequency responses of the nano-cantilever before and after are shown in fig. 4c. By measuring the frequency shift $(6.5 \mathrm{kHz})$ and using a rough estimate of the mass of the carbon deposit (14fg) the mass sensitivity of the device is calculated to approximately $2 \mathrm{ag} / \mathrm{Hz}$. The expected theoretical value, using equation 1 , is approximately $1 \mathrm{ag} / \mathrm{Hz}$, which is in good agreement with the experiment. In this case the minimal frequency shift $(d f)$ that can be measured is approximately $500 \mathrm{~Hz}$, which leads to an absolute minimal detectable mass of approximately $1 \mathrm{fg}$ in these experiments. However, this number can be improved by improving the Q-factor and optimizing the electron detector signal with respect to noise.

\section{CONCLUSIONS}

It has been demonstrated that using a relatively simple process, cantilevers with sub $500 \mathrm{~nm}$ widths and $100 \mathrm{~nm}$ thickness can be fabricated on a wafer scale using UV lithography. It was found that $\mathrm{Al}$ nano-cantilevers can be vertically excited into resonance with a lateral electrode by electrostatic actuation. Through a novel characterization setup, involving a SEM, the Q-factor was measured to approximately 200, which is lower than expected. However, more work needs to be done to investigate why, by improving current anchoring conditions. Finally, measurements of EBID carbon have been done and a mass sensitivity of $2 \mathrm{ag} / \mathrm{Hz}$ has been measured. The SEM characterization technique has shown to be a very versatile and fast tool for measuring nano-cantilevers in vacuum condition. Furthermore, this work demonstrates that a very simple device can be used for high sensitivity mass measurements.

\section{REFERENCES}

[1] K.L. Ekinci, X.M.H. Huang and M.L. Roukes, Appl. Phys. Lett. 84(22), 4469 (2004).

[2] H.P. Lang, R. Berger, J.K. Gimzewski, P. Fornaro, and E. Meyer, Analytica Chimica Acta, 393(1-3), 59 (1999).

[3] J. Yang, T. Ono, and M. Esashi, Sensors and Actuators A 82, 102 (2000).

[4] M. Campione, M. Cartotti, E. Pinotti, A. Sassella, and A. Borghesi, J. Vac. Sci. Technol. A 22(3), 482 (2004).

[5] G. Abadal, Z.J. Davis, B. Helbo, X. Borris, R. Ruiz, A. Boisen, F. Campabadal, J. Esteve, E. Figueras, F. PrezMurano and N. Barniol, Nanotechnology 12, 100 (2001).

[6] Y.T. Yang, K.L Ekinci, X.M.H. Huang, L.M. Schiavone, and M.L. Roukes, Appl. Phys. Lett. 78(2), 162 (2001).

[7] A.N. Cleland and M.L. Roukes, Appl. Phys. Lett. 69(28), 2653 (1996).

[8] E.W. Balch, S.E. Weaver, and R.J. Saia, Proceedings of the SPIE - The International Society for Optical Engineering 922, 387 (1988).

[9] Clark T.-C. Nguyen and Roger T. Howe. Integrated cmos micromechanical resonator high-q oscillator. IEEE Journal of Solid-State Circuits 34(4), 440 (1999).

[10] J. Yang, T. Ono and M. Esasjo, Journal of Microelectromechanical Systems 11, 775 (2002).

[11] A. Husain, J. Hone, Henk W. Ch. Postma, X. M. H. Huang, T. Drake, M. Barbic, A. Scherer and M. L. Roukes, Appl. Phys. Lett. 83(6), 1240 (2003).

[12] Kirsten Ingolf Schiffmann., Nanotechnology 4(3), 163 (1993). 